\title{
Consciência Fonológica e a Aprendizagem da Leitura e Escrita por Adultos
}

\section{Phononlogical Awereness and Adult Literacy}

\author{
Rosane Braga de Melo* \\ Universidade Federal Rural do Rio de Janeiro - UFRRJ, Rio de Janeiro, Rio de \\ J aneiro, Brasil.
}

\section{J ane Correa**}

Universidade Federal do Rio de Janeiro - UFRJ, Rio de Janeiro, Rio de Janeiro, Brasil.

\begin{abstract}
RESUMO
O presente estudo examina o papel de diferentes habilidades de consciência fonológica para a aprendizagem inicial da leitura e da escrita por jovens e adultos no Português Brasileiro, considerando outras habilidades linguísticocognitivas que concorrem para este aprendizado como a habilidade verbal, memória e os níveis iniciais de leitura e de escrita com os quais os participantes ingressaram na Educação de Jovens e Adultos. Foram avaliados no início e ao final do ano letivo, trinta e oito jovens e adultos matriculados em classes de alfabetização no Rio de Janeiro. Os resultados mostraram que o nível inicial de leitura e a habilidade de segmentação foram os melhores preditores do desenvolvimento tanto da leitura quanto da escrita ao final do ano letivo.
\end{abstract}

Palavras-chave: Consciência fonológica, Leitura, Escrita, Adultos.

\begin{abstract}
The present study examined the importance of phonological awareness to adult literacy in Brazilian Portuguese, taking into consideration other cognitive and linguistic skills such as verbal ability, memory and initial levels of reading and writing. Thirty-eight adults in literacy classes in Rio de J aneiro were evaluated at the beginning and the end of the school year. The results showed that the initial level of reading and segmentation skills were the best predictors of the development of reading and writing at the end of the academic year.
\end{abstract}

Keywords: Phonological awareness, Reading, Writing, Adults.

\section{Introdução}

Um olhar sobre os indicadores de analfabetismo no Brasil revela um quadro de exclusão educacional que atinge jovens e adultos, agravado pelo fato de que a maioria dos adultos não alfabetizados 
sequer teve oportunidade de iniciação escolar quando crianças (IBGE, 2001; INEP, 2003; UNESCO, 2006). O quadro de exclusão educacional que atinge a população de baixa renda, a reincidência no fracasso de alfabetização de crianças durante o Ensino Fundamental, a falência das campanhas de alfabetização de adultos que não culminam em uma sistematização de experiências nesse setor e na formação de educadores, são fatores que contribuem para a ampliação do analfabetismo de jovens e adultos brasileiros (BEISIEGEL, 2004; SOARES, 2002). Na ausência de formulações significativas sobre a aquisição da leitura e da escrita dos jovens e adultos, a Educação de Jovens e Adultos (EJA) conta com um reduzido aparato teórico próprio do seu campo de intervenção e materiais adaptados à condição dos leitores iniciantes (OLIVEIRA, 2004).

Nos últimos trinta anos a consciência fonológica tem sido indicada como uma habilidade importante para aquisição da leitura e da escrita em um sistema alfabético de escrita (BABAYIGIT; STAINTHORP, 2011; BRADLEY; BRYANT, 1983; CAPOVI LLA, 2005). A consciência fonológica é a habilidade que permite uma atenção aos sons da fala como entidades independentes do significado, envolvendo, portanto, a atenção explícita para os segmentos que compõem a linguagem falada (BRYANT; BRADLEY, 1987). Por não se constituir como entidade homogênea, a consciência fonológica inclui competências que podem variar em nível de dificuldade e em ordem de aquisição (GOUGH; LARSON; YOPP, 1995; YOPP, 1988). Nesse sentido, competências menos complexas são precursoras da construção de competências fonológicas mais complexas, de tal modo que detectar as sílabas iniciais e a rima das palavras é mais fácil do que detectar fonemas (LUNDBERG; OLOFSSON; WALL, 1980; MOUSINHO; CORREA, 2009), e detectar semelhanças sonoras é mais fácil do que isolar sons nas palavras (STHAL; MURRAY, 1994; YOPP, 1988). Pesquisas em diferentes línguas alfabéticas encontraram resultados semelhantes (COSSU; SHANKWEILER; LIBERMAN; KATZ; TOLA, 1988; JIMÉNEZ; ORTIZ, 1994). Quanto ao nível de segmentação das unidades linguísticas parece haver um progressivo desenvolvimento da consciência da sílaba para a consciência de unidades intrassilábicas, e finalmente, para a consciência dos fonemas (TREIMAN, 1991).

Há suficiente evidência de que a consciência fonológica seja um preditor para suas habilidades futuras na alfabetização (GOSWAMI; BRYANT, 1990; HERRERA; DEFIOR, 2005; KIM, 2009; LANDGRAF; BEYER; HILD; SCHNEIDER; HORN; SCHAADT; FOTH; PANNEKAMP; VAN DER MEER, 2012), que aprendizes com dificuldades na aprendizagem da leitura e da escrita revelam desempenhos inferiores nas tarefas de consciência fonológica (BRYANT; BRADLEY, 1987; GUIMARÃES, 2003), e que programas de treinamento que incluem 
atividades específicas com o objetivo de desenvolver a consciência fonológica aumentam significativamente a possibilidade de êxito na aquisição da leitura e da escrita (CAPOVILLA; CAPOVILLA, 2000; LUNDBERG; FROST; PETERSEN, 1988; SANTOS; MALUF, 2010). No Brasil, nas últimas décadas, uma série de estudos que investigam a relação entre o desenvolvimento metalinguístico, incluindo-se aí tarefas de consciência sintática e morfológica, e a aquisição e o desenvolvimento da leitura e da escrita em crianças (GUIMARÃES; PAULA, 2010; MOTA; ANIBAL; LIMA, 2008) e em adultos (MOTA; CASTRO, 2007), confirmam a contribuição específica da consciência fonológica para a aquisição e incremento do domínio da leitura e da escrita.Tais evidências, contudo, circunscrevem-se, em maior número, aos estudos realizados com crianças, sendo ainda escassos os estudos que envolvem jovens e adultos não alfabetizados.

A experiência de vida e a experiência com a linguagem oral são fatores que poderiam constituir vantagem para a aquisição da leitura e da escrita de jovens e adultos, todavia, as investigações existentes sobre a aquisição da leitura e da escrita de adultos vêm contribuindo para esclarecer que os adultos partilham muitas das suas dificuldades na aprendizagem da leitura e da escrita com as crianças, indicando que os processos cognitivos que participam da aquisição da leitura são similares em adultos e crianças (BELL; PERFETTI, 1994; CHALL, 1987; LANDGRAF; BEYER; HILD; SCHNEIDER; HORN; SCHAADT; FOTH; PANNEKAMP; VAN DER MEER, 2012; PERFETTI; MARRON, 1995).

Níveis limitados de desenvolvimento de consciência fonológica tornam-se uma fonte comum de dificuldades para jovens, adultos e crianças no aprendizado da leitura e da escrita (BELL; PERFETTI, 1994; CARDOSO-MARTINS; CORRÊA; MAGALHÃES, 2010; CHALL, 1987; FOWLER; SCARBOROUGH, 1993; PERFETTI; MARRON, 1995). Investigações realizadas com adultos com dificuldades de aprendizagem (GREENBERG; EHRI; PERIN, 1997; PRATT; BRADY, 1988) e com adultos maus leitores (READ; RUYTER, 1985) mostram uma forte associação entre desenvolvimento de consciência fonológica e alfabetização de jovens e adultos. Os resultados obtidos com adultos não alfabetizados revelam especial dificuldade em tarefas de segmentação e subtração de sons, mas também mostram que os não alfabetizados não são totalmente desprovidos de habilidades de análise fonológica (ADRIÁN; ALEGRIA; MORAIS, 1995; BERTELSON; DE GELDER; TFOUNI; MORAIS, 1989; LUKATELA; CARELLO; SHANKWEILER; LIBERMAN, 1995; MORAIS; BERTELSON; CARY; ALEGRIA, 1986; MORAIS; CARY; ALEGRIA; BERTELSON, 1979; MORAIS; CONTENT; BERTELSON; CARY; KOLINSKY, 1988).

Adultos não alfabetizados podem compreender que as palavras podem ser classificadas de acordo com sua extensão fonológica (KOLINSKY; CARY; MORAIS, 1987), detectar rimas (ADRIÁN; 
ALEGRIA; MORAIS, 1995; BERTELSON; DE GELDER; TFOUNI; MORAIS , 1989; MORAIS; BERTELSON; CARY; ALEGRIA, 1986), subtrair sílabas (MORAIS; BERTELSON; CARY; ALEGRIA 1986) ou a vogal inicial das palavras (BERTELSON; DE GELDER; TFOUNI; MORAIS, 1989). Outros níveis de análise fonológica, como acrescentar ou subtrair uma consoante, constituem especial dificuldade (MORAIS; CARY; ALEGRIA; BERTELSON,1979).

O nexo entre consciência fonológica e alfabetização de jovens e adultos também vem sendo demonstrado em estudos realizados em países que não tem o inglês como primeira língua, como na Espanha (ADRIÁN; ALEGRIA; MORAIS, 1995; JIMÉNEZ; VENEGAS, 2004), Turquia (DURGUNOGLU; ÖNEY, 2002) e Sérvia (LUKATELA; CARELLO; SHANKWEILER; LIBERMAN, 1995). As características da estrutura fonológica das línguas envolvidas nesses estudos e suas complexidades ortográficas mostraram-se fatores relevantes para os resultados encontrados com adultos (ADRIÁN; ALEGRIA; MORAIS, 1995; DURGUNOGLU; ÖNEY, 2002; JIMÉNEZ; VENEGAS, 2004; LUKATELA; CARELLO; SHANKWEILER; LIBERMAN, 1995), tal qual já foi apontado por estudos realizados com crianças de diferentes países (GOSWAMI, 1999; SEYMOUR; ARO; ERSKINE, 2003; WIMMER; GOSWAMI, 1994).

Determinadas unidades fonológicas são mais salientes em uma língua do que em outras, e as mesmas unidades fonológicas não podem predizer o desenvolvimento da leitura e da escrita em diferentes línguas. Parece existir uma dissociação entre a habilidade para a rima e outros níveis de análise fonológica (BERTELSON; DE GELDER; TFOUNI; MORAIS, 1989; ROAZZI; BRYANT; OLIVEIRA; DOWKER, 1994; ROAZZI; DOWKER; BRYANT, 1991), sendo que a habilidade para rimar não demonstra ter particular relevância para a aquisição da leitura de adultos que não tem o inglês como primeira língua (DURGUNOGLU; ÖNEY, 2002; JIMÉNEZ; VENEGAS, 2004; LUKATELA ; CARELLO; SHANKWEILER; LIBERMAN, 1995).

A transparência nas correspondências grafema-fonema de uma língua e a complexidade silábica são fatores que afetam os desempenhos de adultos em tarefas de consciência fonológica. O estudo realizado com servo-croatas indicou que o desempenho no conhecimento de letras se correlaciona com 0 desempenho nas tarefas de consciência fonológica (LUKATELA; CARELLO; SHANKWEILER; LIBERMAN, 1995), e permite domínio mais rápido das competências fundamentais de leitura, ou seja, a aquisição da conversão das sequências de letras em sequências de sons da fala. Para adultos espanhóis leitores menos habilidosos, por exemplo, a complexidade silábica foi relevante no desempenho de tarefas consciência fonológica que exigiram síntese e segmentação de sons (JIMÉNEZ; VENEGAS, 2004).

O presente estudo pretende contribuir para esse debate através de uma pesquisa correlacional de caráter longitudinal sobre a relação 
entre a habilidade de análise fonológica e a aquisição da leitura e da escrita de jovens e adultos brasileiros. Objetiva-se examinar o papel de diferentes habilidades de consciência fonológica para a alfabetização de jovens e adultos no Português Brasileiro, considerando outras habilidades linguístico-cognitivas que concorrem para este aprendizado como a habilidade verbal, memória e os níveis iniciais de leitura e de escrita com os quais os participantes ingressaram na Educação de J ovens e Adultos.

\section{Método}

\subsection{Participantes}

Trinta e oito jovens e adultos ( 11 homens e 27 mulheres), cujas idades variaram entre 16 e 65 anos (idade média $=38$ anos e dois meses), matriculados em turmas de alfabetização em duas instituições de ensino que contemplam a Educação para Jovens e Adultos (EJA) situadas na Zona Sul do Rio de Janeiro, participaram voluntariamente desta investigação, tendo, todos, assinado o Termo de Consentimento Livre e Esclarecido (TCLE). Os participantes são oriundos das Regiões Norte (11\%), Nordeste (45\%), e Sudeste (44\%). Dos $44 \%$ oriundos da Região Sudeste, 30\% nasceu no Estado do Rio de Janeiro. Há uma predominância de adultos em relação aos jovens, sendo que a maioria dos participantes localiza-se na faixa etária de 21 a 40 anos - faixa etária considerada importante para a inserção e permanência no mercado de trabalho. Quanto à atividade profissional verificamos que vinte e oito participantes trabalham e dez não trabalham, sendo que a maioria dos que trabalham possui um emprego fixo, em geral, atividades de baixa remuneração. Quanto à experiência escolar anterior, cerca de $65 \%$ dos participantes teve experiência escolar na infância. A maioria refere-se ao tempo passado na escola quando criança como um tempo em que não se aprendeu nada ou quase nada, e às vezes, no máximo, possibilitou aprender a assinar apenas o próprio nome. Cerca de $45 \%$ dos participantes estava matriculado há mais de um ano na classe de alfabetização de EJA, e 55\% matriculou-se na turma de alfabetização no início do período letivo em que foi realizado o trabalho de campo. Ressalta-se a constante referência dos participantes ao aprendizado da leitura e da escrita como uma forma de garantir a permanência no emprego atual ou ainda como meio de conseguir um emprego melhor remunerado. Cerca de $70 \%$ dos participantes enfatizou a aquisição da leitura e da escrita como modo de ampliar as possibilidades de exercício de uma participação social mais ampla através, por exemplo, da conquista de uma independência em relação aos filhos, companheiros ou mesmo vizinhos para abrir uma conta bancária, 
escrever uma carta para a família, ler a bíblia, ou simplesmente "sair na rua e enxergar". Talvez, a percepção das dificuldades que a exclusão educacional impõe às suas vidas colabore para que esses aprendizes mantenham uma aposta que possivelmente os sustentam em uma sala de aula após um dia exaustivo de trabalho.

\subsection{Tarefas}

\section{Leitura}

Compreendeu uma lista composta por 18 itens distribuídos em 12 palavras (caixa, legumes, batata, tomate, arroz, feijão, colina, safira, luneta, boliche, magia, pirata) e 6 pseudopalavras (zopi, palima, bicato /u/, telube /i/, sipolu, camufe /i/) impressos no centro de folhas de papel ofício. As palavras eram dissílabas e trissílabas, com padrão silábico consoante-vogal (CV) e consoante-vogal-vogal (CVV). As pseudopalavras eram dissílabas e trissílabas, com padrão silábico CV. O coeficiente de confiabilidade da tarefa (Alpha de Cronbach) foi .90 .

\section{Escrita}

Realizada sob a forma de ditado e contou com os mesmos itens da lista da tarefa de leitura. A cada palavra escrita segundo a norma ortográfica foi atribuído um ponto. A confiabilidade da tarefa (Coeficiente Alpha de Cronbach) foi de .82 .

\section{Conhecimento de Letras}

Vinte e três letras maiúsculas seguidas de vinte e três letras minúsculas do alfabeto foram apresentadas em ordem aleatória. $\mathrm{O}$ coeficiente de confiabilidade da tarefa (Alpha de Cronbach) foi de .90 no caso das letras maiúsculas, e Alpha $=0.86$, para as letras minúsculas.

\section{Consciência Fonológica}

\section{J ulgamento de Rima}

A tarefa consistiu de três itens de treinamento e 14 itens experimentais que incluíam palavras dissílabas e trissílabas, com padrão silábico CV e paroxítonas. Em cada item o participante era solicitado a identificar qual, entre três palavras, apresentava uma rima perfeita com a palavra-alvo. Ao contrário dos itens de treinamento não houve feedback nos itens experimentais. Com o objetivo de minimizar a carga da memória de trabalho, as palavras foram representadas por desenhos arranjados horizontalmente em uma folha de papel. O desenho da palavra-alvo aparecia no centro do papel, acima das palavras-teste. O coeficiente de confiabilidade da tarefa (Alpha de Cronbach) foi de .70. 


\section{Julgamento de semelhança de som inicial}

Pretendeu avaliar a habilidade do participante em identificar qual entre três palavras diferentes começava com o mesmo som inicial da palavra-alvo. A tarefa consistia de quatro itens de treinamento e 14 itens experimentais em que foram usados dissílabos com padrão silábico CV e paroxítonas. Os itens foram divididos em dois itens de treinamento e sete itens experimentais de identificação de sílaba inicial, e dois itens de treinamento e sete itens experimentais de identificação de fonema inicial. Foram apresentados inicialmente os itens de treinamento e experimentais relacionados à detecção de semelhança de sílaba inicial, e em seguida os itens de treinamento e experimentais da detecção de semelhança de fonema inicial. Com o objetivo de minimizar a carga da memória de trabalho, as palavras foram representadas por desenhos arranjados horizontalmente em uma folha de papel. O desenho da palavra-alvo aparecia no centro do papel, acima das palavras-teste. O coeficiente de confiabilidade da tarefa (Alpha de Cronbach) foi de .70.

\section{Segmentação}

Foram usados monossílabos, dissílabos, trissílabos e polissílabos, com padrão silábico CV e CCV. A tarefa consistiu de oito itens de treinamento e dezesseis itens experimentais. Os itens foram divididos em quatro de treinamento e oito itens experimentais de segmentação em sílabas, e quatro de treinamento e oito itens de segmentação em fonemas. Apresentamos primeiro os itens de segmentação em sílabas, e logo depois os itens de segmentação em fonemas. As palavras eram apresentadas oralmente, uma de cada vez. Nos itens de segmentação em sílabas os participantes foram solicitados a segmentar as palavras em sílabas e contar o seu número de sílabas. Nos itens de segmentação em fonemas os participantes foram solicitados segmentar as palavras em seus fonemas constituintes e a contar o seu número. Nos itens de treinamento, a marcação da segmentação da palavra em sílabas ou fonemas era realizada com a batida com a palma da mão na mesa. Ao contrário dos itens de treinamento não houve feedback nos itens experimentais. 0 coeficiente de confiabilidade da tarefa (Alpha de Cronbach) foi de.79.

\section{Habilidade verbal}

A habilidade verbal, ou QI Verbal, é avaliada através dos subtestes de Vocabulário, Semelhanças, Aritmética, Dígitos, Informação e Compreensão da Escala de Inteligência Wechsler para adultos - WaisIII (WECHSLER, 1997, adaptação para o Brasil por NASCIMENTO, 2000). 


\section{Compreensão verbal}

Índice fatorial obtido por meio da soma dos escores ponderados dos subtestes de Vocabulário, Semelhanças e Informação da Escala de Inteligência Wechsler para adultos - Wais-III (WECHSLER, 1997, adaptação para o Brasil por NASCIMENTO, 2000).

\section{Memória Operacional}

Índice fatorial obtido por meio da soma dos escores ponderados dos subtestes Aritmética, Dígitos e Sequência de Números e Letras da Escala de Inteligência Wechsler para adultos - Wais-III (WECHSLER, 1997, adaptação para o Brasil por NASCI MENTO, 2000).

\subsection{Procedimento}

No início do período letivo, os participantes realizaram, individualmente, os subtestes verbais da Escala de Inteligência Wechsler para adultos - Wais-III (WECHSLER, 1997, adaptação para - Brasil por NASCIMENTO, 2000) e as tarefas de: consciência fonológica, leitura, escrita e conhecimento de letras. Ao final do ano letivo, os participantes realizaram, também individualmente, apenas as tarefas de leitura e escrita.

\section{Resultados}

A Tabela 1 descreve o desempenho dos jovens e adultos nas diversas habilidades linguístico-cognitivas tomando como medida a proporção média de acertos em cada tarefa. As habilidades de leitura (t (37) = $5.41, p<0.001$ ) como a de escrita $(t(37)=5.48, p<0.001)$ dos jovens e adultos variam significativamente do início ao final do período letivo, indicando relativo progresso dos aprendizes no desenvolvimento destas habilidades. Examinando, ainda, a Tabela 1, constatamos a existência de diferenças significativas entre os desempenhos nas tarefas de leitura e de escrita tanto no início (t(37) $=5.17, \mathrm{p}<0.01)$ como ao final do período letivo $(\mathrm{t}(37)=4.70, \mathrm{p}<$ 0.01 ). Tais resultados revelam que a tarefa de leitura foi sempre mais fácil do que a tarefa de escrita para os jovens e adultos que participaram deste estudo. 
Tabela 1. Média, Desvio-Padrão e Intercorrel ações para Leitura e Escrita ao Final do Período Letivo e Fatores Preditores

\begin{tabular}{|c|c|c|c|c|c|c|c|c|c|c|c|c|c|}
\hline & M & DP & 1 & 2 & 3 & 4 & 5 & 6 & 7 & 8 & 9 & 10 & 11 \\
\hline Leitura Final & 0.53 & $(0.38)$ & $0.74^{* *}$ & $0.56^{* *}$ & $0.33^{*}$ & 0.25 & $0.39 * *$ & $0.31 *$ & $0.40 * *$ & 0.22 & 0.15 & $0.30^{*}$ & -0.15 \\
\hline Escrita Final & 0.35 & $(0.29)$ & $0.54^{* *}$ & $0.60^{* * *}$ & $0.44^{* *}$ & $0.36^{*}$ & $0.37^{*}$ & 0.19 & $0.29 *$ & 0.12 & 0.00 & 0.20 & -0.23 \\
\hline \multicolumn{14}{|l|}{ Fatores Preditores } \\
\hline 1.Leitura Inicial & 0.33 & $(0.29)$ & & $0.66^{* *}$ & 0.25 & 0.26 & 0.06 & $0.42^{* * *}$ & $0.56^{* *}$ & 0.14 & 0.19 & 0.16 & 0.10 \\
\hline 2.Escrita Inicial & 0.15 & $(0.17)$ & & & $0.34^{*}$ & $0.40^{* *}$ & $0.30 *$ & $0.33^{*}$ & $0.40^{* *}$ & $0.31^{*}$ & 0.24 & $0.27^{*}$ & -0.06 \\
\hline 3.Rima & 0.77 & $(0.19)$ & & & & $0.31^{*}$ & $0.42^{* *}$ & -0.04 & 0.15 & -0.02 & 0.09 & 0.00 & -0.14 \\
\hline 4.Som Inicial & 0.62 & $(0.19)$ & & & & & 0.04 & -0.11 & -0.10 & 0.07 & -0.05 & 0.16 & -0.25 \\
\hline 5.Segmentação & 0.44 & $(0.18)$ & & & & & & -0.09 & -0.01 & 0.24 & 0.00 & $0.31^{*}$ & - \\
\hline 6.Letra Maiúscula & 0.79 & $(0.21)$ & & & & & & & $0.87^{* * *}$ & 0.19 & $0.29 *$ & -0.01 & 0.19 \\
\hline 7.Letra Minúscula & 0.73 & $(0.20)$ & & & & & & & & 0.11 & 0.26 & -0.09 & $0.29 *$ \\
\hline 8.Habilidade & 80.71 & $(5.76)$ & & & & & & & & & $0.75^{* *}$ & $0.78^{* * *}$ & $0.33^{*}$ \\
\hline 9.Compreensão & 82.89 & $(5.07)$ & & & & & & & & & & $0.50 * *$ & $0.48^{* *}$ \\
\hline 10.Memória & 84.53 & $(8.42)$ & & & & & & & & & & & 0.14 \\
\hline 11.Idade & & & & & & & & & & & & & _- \\
\hline
\end{tabular}

Em relação às tarefas de consciência fonológica, a Tabela 1 mostra que os desempenhos dos participantes no início do período letivo variaram significativamente em função das competências diferentes de análise fonológica envolvidas nas tarefas, indicando que as tarefas podem ser hierarquizadas pelo grau de dificuldade $F(2.74)=39.21 \mathrm{p}$ $<0.01$. A utilização do post-hoc teste (Newman Keuls) mostrou que os participantes apresentaram desempenhos significativamente superiores nas tarefas de detecção de rima em relação às demais tarefas $(p<0.05)$. Constatou-se, também, que há diferenças significativas entre as proporções médias dos escores obtidos pelos participantes nas tarefas de detecção de semelhança de som inicial e de segmentação de sons. Uma hierarquia de dificuldades entre as tarefas pode ser, então, estabelecida: a tarefa de detecção de rima podendo ser considerada a mais fácil dentre as tarefas, seguida das tarefas de detecção de semelhança de som inicial e segmentação de sons.

$\mathrm{Na}$ tarefa de conhecimento de letras a resposta foi considerada correta quando o nome da letra fosse nomeada apropriadamente. Como pode ser visto na Tabela 1, os participantes apresentam um desempenho superior no conhecimento de letras maiúsculas, em relação às letras minúsculas $(\mathrm{t}(37)=3.75, \mathrm{p}<0.01)$. Uma explicação possível para esses resultados diz respeito às formas mais simples das letras maiúsculas em relação às letras minúsculas, facilitando, portanto, o seu reconhecimento.

\subsection{A relação entre a consciência fonológica e demais habilidades linguístico-cognitivas e a leitura e escrita de jovens e adultos ao final do período letivo}


Para examinar a relação entre o relativo progresso das habilidades de leitura e escrita dos jovens e adultos ao final do período letivo e suas habilidades de análise fonológica, correlacionamos os desempenhos dos aprendizes nestas tarefas. Os resultados dessas correlações podem ser vistos na Tabela 1, incluindo, também, as correlações envolvendo o nível de leitura e o nível de escrita apresentados pelos aprendizes no início do período letivo, o conhecimento de letras maiúsculas e minúsculas, a habilidade verbal, o índice de compreensão verbal, o índice de memória operacional e a idade dos participantes.

O desempenho na tarefa de leitura ao final do período letivo correlacionou-se significativamente com o desempenho nas tarefas de consciência fonológica de julgamento de rima e segmentação, com o nível de leitura e o nível de escrita apresentados no início do período letivo, com o conhecimento de letras e com o Índice de Memória Operacional. Por sua vez, o desempenho na tarefa de escrita ao final do período letivo correlacionou-se significativamente com o desempenho nas tarefas de consciência fonológica de julgamento de rima, julgamento de semelhança de som inicial e segmentação, com o nível de leitura e o nível de escrita apresentados no início do período letivo, e com o conhecimento de letras minúsculas. Tendo em vista esse padrão de intercorrelações, análises de regressões múltiplas foram calculadas para avaliar a especificidade da contribuição das tarefas de consciência fonológica para as habilidades de leitura e escrita do final do período letivo. As análises de regressão foram calculadas separadamente para a leitura e para a escrita.

Para examinar se as habilidades de consciência fonológica seriam os melhores preditores para o desempenho em leitura dos jovens e adultos foi realizada uma análise de regressão múltipla (stepwise) tendo como fatores: o julgamento de rima, a segmentação de sons, o nível de leitura e de escrita inicial, o conhecimento de letras maiúsculas e minúsculas e o Índice Memória Operacional. Os resultados dessa análise sugerem um modelo no qual a combinação do nível de leitura no início do período letivo e a tarefa de segmentação de sons explicam $67 \%$ da variabilidade da habilidade de leitura no final do período letivo (Tabela 2). Observa-se que a habilidade de segmentação é uma boa preditora do progresso em leitura alcançado pelos jovens e adultos mesmo levando-se em consideração a variabilidade já atribuída no modelo proposto às habilidades iniciais de leitura dos aprendizes. 
Tabela 2. Análise de Regressão Múltipla para a Habilidade de Leitura ao Final do Período Letivo

\begin{tabular}{cccccccc}
\hline Variáveis & B & Std. Error & Beta & R & R2 & Mudança em R2 & F \\
\hline Leitura inicial & 0.80 & 0.11 & $0.72^{* *}$ & 0.74 & 0.55 & 0.55 & $43.31^{* *}$ \\
Segmentação & 0.64 & 0.18 & $0.35^{* *}$ & 0.82 & 0.67 & 0.12 & $12.45^{* *}$ \\
\hline${ }^{*} \mathrm{p}<0.05 ;{ }^{* *} \mathrm{p}<0.01$ & & & & & &
\end{tabular}

Com o objetivo de verificar o papel das habilidades de consciência fonológica no conjunto de outras habilidades linguístico-cognitivas para o relativo progresso dos jovens e adultos no aprendizado da escrita, foi realizada uma análise de regressão múltipla (stepwise) tendo como fatores: o julgamento de rima, o julgamento de semelhança de som inicial, a segmentação de sons, os níveis de leitura e de escrita inicial dos aprendizes e conhecimento de letras. Os resultados desta análise, conforme mostra a Tabela 3, revelaram que os melhores preditores para a habilidade de escrita dos jovens e adultos ao final do período letivo foram o nível de leitura apresentado no início do período letivo e a tarefa de segmentação de sons.

Tabela 3. Análise de Regressão Múltipla para a Habilidade de Escrita ao Final do Período Letivo

\begin{tabular}{cccccccc}
\hline Variáveis & B & Std. Error & Beta & R & R2 & Mudança em R2 & F \\
\hline Leitura inicial & 0.61 & 0.12 & $0.58^{* *}$ & 0.61 & 0.37 & 0.37 & $20.88^{* *}$ \\
Segmentação & 0.73 & 0.20 & $0.41^{* *}$ & 0.73 & 0.54 & 0.17 & $12.93^{* *}$ \\
\hline${ }^{*} \mathrm{p}<0.05^{* *} \mathrm{p}<0.01$ & & & & & & &
\end{tabular}

O modelo sugere que juntos o nível de leitura inicial e o desempenho na tarefa de segmentação explicam $54 \%$ de variação da habilidade de escrita no final do período letivo. De forma semelhante ao modelo proposto anteriormente para a leitura, constamos que a habilidade de segmentação continua contribuindo significativamente para a habilidade de escrita final, mesmo tendo sido considerado primeiramente pelo modelo o efeito de variações no nível de leitura inicial dos aprendizes.

\section{Discussão}

Tomar a leitura e a escrita como um conjunto de habilidades permite defender a especificidade do processo de alfabetização como um período de tempo reservado para aprender a ler e a escrever. Aprender a ler faz parte de um longo processo onde 0 reconhecimento de palavras é uma das primeiras e importantes tarefas do aprendiz, do mesmo modo que aprender a escrever depende de um longo percurso, mais longo do que a leitura, no qual 
a habilidade de soletrar é apenas uma dentre as várias que farão parte desse período inicial. Considera-se fundamental no presente trabalho discutir sobre o papel das habilidades de consciência fonológica, tomadas em relação a outras habilidades linguísticocognitivas, no ato de ler e de escrever.

Nossos resultados confirmam a importância da consciência fonológica para a aquisição da leitura e da escrita de jovens e adultos brasileiros, especialmente da habilidade de segmentação. Além de confirmar as evidências que sugerem que as performances em tarefas de consciência fonológica são afetadas pelas demandas cognitivas das tarefas (STHAL; MURRAY, 1994; YOPP, 1988), os resultados também estão de acordo com as pesquisas realizadas com crianças e adultos brasileiros (CARDOSO-MARTINS, 1995; ROAZZI; BRYANT; OLIVEIRA; DOWKER, 1994; ROAZZI; DOWKER; BRYANT 1991), em relação à contribuição mais modesta da tarefa de detecção de rima para o desenvolvimento da leitura e da escrita na língua Portuguesa falada no Brasil.

Se por um lado, os adultos possuem capacidade de realizar análise fonológica da palavra, daí suas performances superiores nas tarefas de detecção de semelhança de sons iniciais e finais, por outro o aprendizado da língua escrita parece requerer uma habilidade mais refinada para segmentar as palavras. O que confirma a concepção de um desenvolvimento da habilidade de leitura pressupondo um aprimoramento da estratégia alfabética que por sua vez é acompanhada pelo desenvolvimento da consciência fonológica (EHRI, 1995; LANDGRAF; BEYER; HILD; SCHNEIDER; HORN; SCHAADT; FOTH; PANNEKAMP; VAN DER MEER, 2012; STHAL; MURRAY, 1994), fazendo com que mais adiante a conquista de uma análise segmentar mais aprimorada acompanhe os progressos na leitura.

O nível inicial de leitura revelou-se como fator que prediz tanto a leitura quanto a escrita no final do período letivo. Os níveis iniciais de leitura expressam também o nível de análise fonológica conquistada pelo aprendiz além de seus conhecimentos iniciais acerca das relações grafofonêmicas. Tais habilidades e conhecimentos podem favorecer desde o início do período letivo o aprimoramento gradativo de representações ortográficas das palavras necessárias à leitura fluente. Os níveis iniciais de leitura também contribuem para o desenvolvimento da escrita, confirmando que a habilidade de leitura é um importante instrumento para ajudar o aprendiz a consolidar o conhecimento ortográfico necessário para escrever de acordo com as convenções da linguagem escrita. Na literatura PSI a escrita vem sendo definida como uma habilidade que possui uma exigência maior em relação à leitura no que se refere à análise segmentar (CAPOVILLA, 2005; MORAIS, 1996).

Quanto ao conhecimento de letras, os resultados revelam que embora não seja um fator crítico no desenvolvimento das habilidades 
de leitura e de escrita de adultos brasileiros, foram encontradas correlações significativas entre o conhecimento de letras e o desempenho na tarefa de leitura e na tarefa de escrita no final do período letivo. Os aprendizes que conhecem as letras estarão diante de menos uma dentre tantas demandas no percurso da aquisição da leitura e da escrita. Mas esse conhecimento não elucida as relações entre sons e letras existentes em um sistema ortográfico translúcido como o português ou opaco como o inglês, tampouco engendra uma compreensão de como funciona o princípio alfabético, a exemplo do que nos revelam alguns participantes do presente estudo que quando apresentados aos itens da tarefa de leitura, nomeavam corretamente todas as letras de uma dada palavra e logo em seguida enunciavam: "Mas eu não sei juntar".

As medidas de habilidade verbal não se constituíram fatores preditores para a leitura e para a escrita de jovens e adultos brasileiros. Esses resultados estão de acordo com os estudos longitudinais que tratam da aquisição da leitura e da escrita de crianças (BRADLEY; BRYANT, 1985; LUNDBERG; OLOFSSON; WALL, 1980). O único estudo longitudinal com adultos reportado no presente estudo não avaliou capacidades cognitivas gerais através de um teste padronizado, mas sim através de tarefas construídas especificamente para avaliar tais capacidades (DURGUNOGLU; ÖNEY, 2002). A correlação encontrada entre o Índice de Memória Operacional e o desempenho na leitura no final do período letivo é congruente com as investigações que estabeleceram uma relação entre dificuldades na leitura e na escrita de crianças e adultos e o desempenho em testes que avaliam a memória operacional (BRADY, 1997; SNOWLING, 2004). Se a conversão de uma sequência de letras em uma sequência sonora for rápida, a memória e atenção podem se ater no significado do que está sendo lido. Se a conversão de uma sequência de letras em uma sequência sonora for lenta, então os sons iniciais podem ser perdidos, uma vez que a capacidade da memória operacional é limitada e o tempo de armazenamento é curto. Logo, o aprendiz que possui poucas regras de transcrição fonográficas tem uma capacidade de decodificação lenta, de tal modo que a memória operacional, que possui capacidade limitada, é sobrecarregada, restando poucos recursos para a compreensão das palavras.

As dificuldades no desenvolvimento da leitura estão relacionadas às dificuldades em estabelecer correspondências entre sons e letras e, uma vez que a capacidade da memória de curto prazo é limitada, um comprometimento na codificação fonológica restringe o número de itens verbais que podem ser retidos na memória e causa um impacto nas tarefas que exigem memória (SNOWLING, 2004; WAGNER; TORGESEN, 1987). Um problema que pode afetar a leitura porque reduz a habilidade para combinar sons durante a leitura (TORGESEN; 
WAGNER; BALTHAZAR; DAVIS; MORGAN; SIMMONS; STAGE; ZIRPS, 1989).

\section{Conclusões}

Os resultados da presente investigação confirmam a hipótese inicial sobre a contribuição específica da consciência fonológica para o desenvolvimento da habilidade de leitura e de escrita de jovens e adultos, levando em conta a influência de outros fatores associados relacionados a este desenvolvimento como o conhecimento de letras, níveis iniciais de leitura e de escrita e a inteligência verbal. Em função da complexidade que os atuais estudos indicam entre as habilidades metalinguísticas e o aprendizado da leitura e da escrita, recomendam-se novas pesquisas que incluam a consciência morfossintática e a consciência fonológica, particularmente em estudos de intervenção visando verificar se uma programação com atividades voltadas para o desenvolvimento das habilidades metalinguísticas conduz a melhores desempenhos em leitura e escrita de jovens e adultos.

Por fim, os resultados do presente estudo têm implicações teóricas e práticas. No plano teórico, contribui para o conjunto de evidências de pesquisas realizadas no âmbito da psicologia cognitiva que investigam a relação entre a consciência fonológica e alfabetização de crianças, jovens e adultos em diferentes países. A forte conexão entre as tarefas que envolvem rima e o início da leitura na língua inglesa (GOSWAMI, 1999; GOSWAMI; BRYANT, 1990) não tem sido encontrada em ortografias mais transparentes em relação às regularidades nas correspondências entre grafemas e fonemas (GOSWAMI, 1999; WIMMER; GOSWAMI, 1994). As sequências ortográficas que representam a rima são bastante salientes na língua inglesa em função do número de monossílabos que fazem parte dos livros que as crianças encontram nos níveis iniciais da escolarização. Levando em conta as características da língua Portuguesa falada no Brasil, talvez seja possível obter vantagem inicialmente em atividades de segmentação de palavras em sílabas e depois em unidades intrassilábicas, por ser a sílaba uma unidade saliente na nossa língua. No plano da prática, pode contribuir para esclarecer sobre as habilidades que devem ser desenvolvidas em programas de alfabetização de jovens e adultos para promover a aprendizagem da leitura e da escrita, além de fomentar uma reflexão junto aos educadores sobre a necessidade de desenvolvimento de habilidades que podem ser tomadas como pré-requisito para a compreensão do princípio alfabético. Uma investigação realizada com alfabetizandos jovens e adultos brasileiros e reportada por Morais (2010) 
demonstrou o quanto atividades que envolvem sílabas parecem necessárias para o domínio do sistema de escrita pelos aprendizes.

De certo que não acreditamos que essas habilidades sejam responsáveis por todas as dificuldades que afetam a alfabetização de jovens e adultos no nosso país. Os fatores sociais, emocionais, motivacionais certamente exercem forte influência nesse aprendizado. Além de diferenças óbvias como a idade e a experiência de vida existem também as diferenças em relação aos objetivos e motivações que diferem as crianças dos jovens e estes dos adultos. Se todo aprendizado implica suportar o próprio erro e as limitações a que todos estamos sujeitos, o medo do insucesso e o sentimento de incapacidade podem se constituir obstáculos durante o aprendizado de jovens e adultos tardiamente escolarizados.

Enfim, os resultados do presente estudo mostram que a aquisição da leitura e da escrita de jovens e adultos brasileiros tardiamente escolarizados segue os mesmos princípios que, de forma geral, governam o aprendizado da leitura e da escrita em um sistema alfabético de escrita. Em uma sociedade letrada, o sistema de escrita ainda permanece como um meio privilegiado de veicular informação e o aprender a ler e a escrever permanece como um ideal libertário, por ser uma conquista que envolve procedimentos geradores de novas aprendizagens: aprender a ler e depois ler para aprender. Aprender a ler e a escrever é apenas um primeiro passo de um longo processo, mas se a leitura e a escrita podem ser tomadas como artes, é por conceder ao leitor e ao escritor eficiente um privilégio de exercício contínuo de criação. Não é justo que tantos sejam excluídos logo nos primeiros passos.

\section{Referências}

ADRIÁN, J. A.; ALEGRIA, J.; MORAIS, J. Metaphonological abilities of Spanish illiterate adults. I nternational Journal of Psychology, Montréal, v. 30, n. 3, p. 329-353, 1995.

BABAYIGIT, S.; STAINTHORP, R. Modeling the Relationships between Cognitive-Linguistic Skills and Literacy Skills: New Insights from a Transparent Orthography. Journal of Educational Psychology, Arlington, v. 103, n. 1, p. 169-189, 2011.

BEISIEGEL, C. R. Estado e educação popular. Brasília, DF: Líber Livro, 2004.

BELL, L. C.; PERFETTI, C. A. Reading skill: Some adult comparisons. J ournal of Educational Psychology, Arlington, v. 86, n. 2, p. 244255, 1994.

BERTELSON, P.; DE GELDER, B.; TFOUNI, L. V.; MORAIS, J. Metaphonological abilities of adult illiterates: New evidence of 
heterogeneity. European Journal of Cognitive Psychology, London, v. 1, n. 3, p. 239-250, 1989.

BRADLEY, L.; BRYANT, P. E. Categorizing sounds and learning to read: A causal connection. Nature, v. 301, n. 5899, p. 419-421, 1983.

BRADLEY, L.; BRYANT, P. E. Rhyme and reason in reading and spelling. Ann Arbor, MI: University of Michigan Press, 1985.

BRADY, S. A. Ability to encode phonological representations: $\mathrm{Na}$ underlying difficulty for poor readers. In: BLACHMAN, B. (Ed.), Foundations of reading acquisition and dislexia: implications for early intervention. Mahwah, NJ : Lawrence Erlbaum Associates, 1997, p. 21-48.

BRYANT, P. E.; BRADLEY, L. Problemas de leitura na criança. Porto Alegre, RS: Artes Médicas, 1987.

CAPOVILLA, A. G. S.; CAPOVILLA, F. C. Efeitos do treino de consciência fonológica em crianças com baixo nível sócio-econômico. Psicologia: Reflexão e Crítica, Porto Alegre, v. 13 , n. 1, p. 7-24, 2000.

CAPOVILLA, F. (ORG.). Os novos caminhos da alfabetização infantil. São Paulo, SP: Memnon, 2005.

CARDOSO-MARTINS, C. Sensitivity to rhymes, syllables, and phonemes in literacy acquisition in Portuguese. Reading Research Quarterly, Newark, v. 30, n. 4, p. 808-827, 1995.

CARDOSO-MARTINS, C.; CORRÊA, M. F.; MAGALHÃES, L. F. S. Dificuldade específica de aprendizagem da leitura e da escrita. In: MALLOY-DINIZ, L.F.; FUENTES, D.; MATTOS, P.; ABREU, N. (Eds). Avaliação Neuropsicológica. Porto Alegre: Artmed, 2010.

CHALL, J. S. Reading development in adults. Annals of Dyslexia, Baltimore, v. 37, n. 1, 240-251, 1987.

COSSU, G.; SHANKWEI LER, D.; LIBERMAN, I. Y.; KATZ, L.; TOLA, G. Awareness of phonological segments and reading ability in Italian children. Applied Psycholinguistcs, Cambridge, v. 9, n. 1, p. 1-16, 1988.

DURGUNOGLU, A. Y.; ÖNEY, B. Phonological awareness in literacy acquisition: It's not only for children. Scientific Studies of Reading, Philadelphia, v. 6, n. 3, p. 245-266, 2002.

EHRI, L. C. Phases of development in learning to read words by sight. J ournal of Research in Reading, London, v. 18, n. 2, p. 115-125, 1995.

FOWLER, A. E.; SCARBOROUGH, H. S. Should reading disabled adults be distinguished from other adults seeking literacy instruction? A review of theory and research. (Technical Report No. 93-6). Philadelphia: University of Pennsylvania, National Center on Adult Literacy, 1993.

GOSWAMI, U. The relationship between phonological awareness and orthographic representation in different ortographies. In: HARRIS, M.; 
HATANO, G. (Eds.), Learning to read and write: a crooslinguistic perspective .Cambridge, MA: Cambridge University Press, 1999, p. 134-156.

GOSWAMI, U.; BRYANT, P. Phonological skills and learning to read. Hove, UK, Lawrence Erlbaum, 1990.

GOUGH, P. B.; LARSON, K. C.; YOPP, H. A estrutura da consciência fonológica. In: CARDOSO-MARTINS, C. (Org.). Consciência fonológica \& alfabetização. Rio de Janeiro, RJ : Vozes, 1995, p. 1535.

GREENBERG, D.; EHRI, L. C.; PERIN, D. Are word-reading processes the same or different in adult literacy students and third-fifth graders matched for reading level? Journal of Education Psychology, Arlington, v. 89, n. 2, p. 262-275, 1997.

GUIMARÃES, S. R. K. Dificuldades no Desenvolvimento da Lectoescrita: O Papel das Habilidades Metalinguísticas. Psicologia: Teoria e Pesquisa. Brasília, v. 19, n. 1, p. 33-45, 2003.

GUIMARÃES, S. R. K.; PAULA, F. V. O papel da consciência morfossintática na aquisição e no aperfeiçoamento da leitura e da escrita. Educar em Revista, Dossiê Metalinguagem e escrita, Curitiba, n. 38, p. 93-111, 2010.

HERRERA, L; DEFIOR, S. Una Aproximación al Procesamiento Fonológico de los Niños Prelectores: Conciencia Fonológica, Memoria Verbal a Corto Plazo y Denominación. Psykhe, Santiago, v. 14, n. 2, 2005.

INEP. Mapa do Analfabetismo no Brasil. Brasília: MEC/INEP, 2003. IBGE. Censo demográfico 2000. Características da população e dos domicílios: resultados do universo. Rio de Janeiro, RJ : IBGE, 2001.

JIMÉNEZ, J. E.; ORTIZ, M. R. Phonological awareness in learning literacy. I ntellectica, Paris, v. 18, n. 1, p. 155-181, 1994.

JIMÉNEZ, J. E.; VENEGAS, E. Defininig phonological awareness and its relationship to reading skills in low-literacy adults. J ournal of Education Psychology, Arlington, v. 96, n. 4, p. 789-810, 2004.

KIM, Y. The foundation of literacy skills in Korean: the relationship between letter-name knowledge and phonological awareness and their relative contribution to literacy skills. Reading and Writing: : An I nterdisciplinary J ournal, Amsterdam, v. 22, n. 8, p. 907-931, 2009.

KOLINSKY, R.; CARY, L.; MORAIS, J. Awareness of words as phonological entities: The role of literacy. Applied Psycholinguistics, Cambridge, v. 8, n. 3, p. 223-232, 1987.

LANDGRAF, S. ; BEYER, R. ; HILD, I.; SCHNEIDER, N.; HORN, E.; SCHAADT, G.; FOTH, M.; PANNEKAMP, A. ; VAN DER MEER, E. Impact of phonological processing skills on written language acquisition in illiterate adults. Developmental Cognitive Neuroscience, Amsterdam, v. 2, n. 1, p. 129-138, 2012. 
LUKATELA, K.; CARELLO, C.; SHANKWEILER, D.; LIBERMAN, I. Y. Phonological awareness in illiterates: Observations from SerboCroatian. Applied Psycholinguistics, Cambridge, v. 16, n. 4, p. 463-487, 1995.

LUNDBERG, I.; OLOFSSON, A.; WALL, S. Reading and spelling skills in the first school years predicted from phonemic awareness skills in kindergarten. Scandinavian Journal of Psychology, Noruega, v. 21, n. 1, p. 159-173, 1980.

LUNDBERG, I.; FROST, J.; PETERSEN, O. P. Effects of an extensive program for stimulating phonological awareness in preschool children. Reading Research Quarterly, Newark, v. 23, n. 3, p. 263-284, 1988.

MORAIS, A. G. A consciência fonológica de alfabetizandos jovens e adultos e sua relação com o aprendizado da escrita alfabética. In: ALBUQUERQUE, E. B. C.; LEAL, T. F; MORAIS, A. G. (Orgs.). Alfabetizar letrando na EJ A: fundamentos teóricos e propostas didáticas. Belo Horizonte: Autêntica Editora, 2010, p. 49-69.

MORAIS, J. A Arte de Ier. São Paulo, SP: Universidade Estadual Paulista, 1996.

MORAIS, J.; BERTELSON, P.; CARY, L.; ALEGRIA, J. Literacy training and speech segmentation. Cognition, Amsterdam, v. 24, n. 1-2, p. 45-64, 1986.

MORAIS, J.; CARY, L.; ALEGRIA, J.; BERTELSON, P. Does awareness of speeech as a sequence of phones arise spontaneously? Cognition, Amsterdam, v. 7, n. 4, p. 323-331, 1979.

MORAIS, J.; CONTENT, A.; BERTELSON, P.; CARY, L.; KOLINSKY, R. Is there a critical period for the acquisition of segmental analysis? Cognitive Neuropsychology, Londres, v. 5, n. 3, p. 347-352, 1988. MOTA, M. M. P. E.; ANIBAL, L.; LIMA, S. A Morfologia Derivacional Contribui para a Leitura e Escrita no Português? Psicologia: Reflexão e Crítica, Porto Alegre, v. 21, n. 2, p. 311-318, 2008.

MOTA, M. M. E. P.; CASTRO, N. R. Alfabetização e consciência metalinguística: um estudo com adultos não alfabetizados. Estudos de Psicologia, Campinas, v. 24, n. 2, p. 169-179, 2007.

MOUSINHO, R.; CORREA, J. Habilidades linguístico-cognitivas em leitores e não-leitores. Pró-Fono Revista de Atualização Científica, São Paulo, v. 21, n. 2, p. 113-8, 2009.

NASCIMENTO, E. Validação e adaptação do teste WAI S-I I I para um contexto brasileiro. 361p Tese (Doutorado em Psicologia, Universidade de Brasília, Brasília, 2000.

OLIVEIRA, J. B. A. Alfabetização de crianças e adultos: novos parâmetros. Belo Horizonte, MG: Alfa Educativa, 2004.

PERFETTI, C. A.; MARRON, M. A. Learning to read: literacy acquisition by children and adults. Philadelphia, PA: National Centre on Adult Literacy, 1995. 
PRATT, A.; BRADY, S. Relation of phonological awareness to reading disability in children and adults. Journal of Education Psychology, Arlington, v. 80, n. 3, p. 319-323, 1988.

READ, C.; RUYTER, L. Reading and spelling skills in sdults of low literacy. Remedial and Special Education (RASE), Austin, v. 6, n. 6, p. 43-51, 1985.

ROAZZI, A.; BRYANT, P. E.; OLIVEIRA, G. G.; DOWKER, A. As habilidades linguísticas dos repentistas e sua relação com o nível de consciência fonológica. Cadernos de Estudos Lingüísticos, Campinas, v. 26, p. 35-158, 1994.

ROAZZI, A.; DOWKER, A.; BRYANT, P. E. A arte do repente e consciência fonológica. Revista Brasileira de Estudos Pedagógicos, Brasilia, v. 72, n. 172, p. 291-317, 1991.

SANTOS, M, J.; MALUF, M. R. Consciência fonológica e linguagem escrita: efeitos de um programa de intervenção. Educar em Revista, Curitiba, n. 38, p. 57-71, 2010.

SEYMOUR, P. H. K.; ARO, M.; ERSKINE, J. M. Foundation literacy acquisition in European orthographies. British Journal of Psychology, London, v. 94, n. 2, p. 143-174, 2003.

SNOWLING, M. J. Dislexia. São Paulo, SP: Livraria Santos Editora, 2004.

SOARES, L. Educação de jovens e adultos. Rio de Janeiro, RJ: DP\&A, 2002.

STAHL, S. A.; MURRAY, B. A. Defining phonological awareness and its relationship to early reading. Journal of Educational Psychology, Arlington, v. 86, n. 2, p. 221-234, 1994.

TORGESEN, J. K.; WAGNER, R. K.; BALTHAZAR, M.; DAVIS, C.; MORGAN, S.; SIMMONS, K.; STAGE, S.; ZIRPS, F. Development and individual differences in performance on phonological syntheses tasks. Journal of Experimental Child Psychology, Amsterdam, v. 47, n. 3, p. 491-505, 1989.

TREIMAN, R. Children's spelling errors on syllable-initial consonant clusters. Journal of Educational Psychology, Arlington, v. 83, n. 3, p. 346-360, 1991.

UNESCO. Alfabetização para a vida: relatório de monitoramento global de educação pata todos; relatório conciso. Brasília: UNESCO, 2006.

WAGNER, R. K.; TORGESEN, J. K. The nature of phonological processing and its causal role in the acquisition of reading skills. Psychological Bulletin, Washington, v. 101, n. 2, p. 192-212, 1987. WIMMER, H.; GOSWAMI, U. The influence of orthographic on reading development: Word recognition in English and German children. Cognition, Amsterdam, v. 51, n. 1, p. 91-103, 1994.

YOPP, $H$. The validity of phonemic awarenes tests. Reading Research Quarterly, Newark, v. 23, n. 2, p. 159-177, 1988. 


\section{Endereço para correspondência \\ Rosane Braga de Melo}

Universidade Federal Rural do Rio de Janeiro, Instituto de Educação, Departamento de Psicologia. BR 465, Km 07, CEP: 23890-000 - Seropédica, RJ - Brasil

Endereço eletrônico: rosanebm@yahoo.com.br

\section{Jane Correa}

Universidade Federal do Rio de Janeiro, Instituto de Psicologia, Departamento de Psicologia Geral e Experimental.

Av. Pasteur, 250- Pavilhão Nilton

Campos - Praia Vermelha, CEP 22290-240 - Rio de Janeiro, RJ - Brasil

Endereço eletrônico: jncrrea@gmail.com

Recebido em: 31/08/2012

Reformulado em: 30/01/2013

Aceito para publicação em: 07/03/2013

Acompanhamento do processo editorial: Adriana Benevides Soares

\section{Notas}

* Doutorado em Psicologia pela Universidade Federal do Rio de Janeiro. Professora Adjunta do Departamento de Psicologia da Universidade Federal Rural do Rio de Janeiro, e da Pós-Graduação em Psicologia da UFRRJ .

** Doutorado em Psicologia do Desenvolvimento pela Universidade de Oxford, Inglaterra e Estágio Pós-doutoral realizado no Instituto de Educação da Universidade de Londres, Inglaterra. Professora Associada do Departamento de Psicologia Geral e Experimental e da Pós-Graduação em Psicologia da Universidade Federal do Rio de Janeiro. Pesquisadora Nível 2 do CNPq.

***A primeira autora agradece ao apoio do CNPq pela Bolsa de Doutoramento a ela concedida, sem a qual a realização da presente investigação não teria sido possível. 